\title{
Results of volume-staged fractionated Gamma Knife radiosurgery for large complex arteriovenous malformations: obliteration rates and clinical outcomes of an evolving treatment paradigm
}

\author{
Alberto Franzin, MD, ${ }^{1}$ Pietro Panni, MD, ${ }^{1}$ Giorgio Spatola, MD, ${ }^{1}$ Antonella del Vecchio, PhD, ${ }^{2}$ \\ Alberto L. Gallotti, MD, ${ }^{1}$ Carmen R. Gigliotti, MSc, ${ }^{2}$ Andrea Cavalli, MD, ${ }^{1}$ Carmine A. Donofrio, MD, ${ }^{1}$ \\ and Pietro Mortini, MD ${ }^{1}$
}

Departments of ${ }^{1}$ Neurosurgery and Radiosurgery, and ${ }^{2}$ Medical Physics, IRCCS San Raffaele Scientific Institute, Milan, Italy

OBJECTIVE There are few reported series regarding volume-staged Gamma Knife radiosurgery (GKRS) for the treatment of large, complex, cerebral arteriovenous malformations (AVMs). The object of this study was to report the results of using volume-staged Gamma Knife radiosurgery for patients affected by large and complex AVMs.

METHODS Data from 20 patients with large AVMs were prospectively included in the authors' AVM database between 2004 and 2012. A staging strategy was used when treating lesion volumes larger than $10 \mathrm{~cm}^{3}$. Hemorrhage and seizures were the presenting clinical feature for $6(30 \%)$ and $8(40 \%)$ patients, respectively. The median AVM volume was 15.9 $\mathrm{cm}^{3}$ (range 10.1-34.3 $\left.\mathrm{cm}^{3}\right)$. The mean interval between stages ( \pm standard deviation) was 15 months ( \pm 9 months). The median margin dose for each stage was $20 \mathrm{~Gy}$ (range 18-25 Gy).

RESULTS Obliteration was confirmed in $8(42 \%)$ patients after a mean follow-up of 45 months (range 19-87 months). A significant reduction (> 75\%) of the original nidal volume was achieved in $4(20 \%)$ patients. Engel Class I-II seizure status was reported by $75 \%$ of patients presenting with seizures (50\% Engel Class I and $25 \%$ Engel Class II) after radiosurgery. After radiosurgery, $71.5 \%$ (5/7) of patients who had presented with a worsening neurological deficit reported a complete resolution or amelioration. None of the patients who presented acutely because of hemorrhage experienced a new bleeding episode during follow-up. One (5\%) patient developed radionecrosis that caused sensorimotor hemisyndrome. Two (10\%) patients sustained a bleeding episode after GKRS, although only $1(5 \%)$ was symptomatic. High nidal flow rate and a time interval between stages of less than 11.7 months were factors significantly associated with AVM obliteration ( $p=0.021$ and $p=0.041$, respectively). Patient age younger than 44 years was significantly associated with a greater than $75 \%$ reduction in AVM volume but not with AVM obliteration $(p=0.024)$.

CONCLUSIONS According to the results of this study, volume-staged GKRS is an effective and safe treatment strategy for large, complex, cerebral AVMs for which microsurgery or endovascular approaches could carry substantially higher risks to the patient. Radiation doses up to $20 \mathrm{~Gy}$ can be safely administered. The time interval between stages should be shorter than 11.7 months to increase the chance of obliteration. High nidal flow and a patient age younger than 44 years were factors associated with nidus obliteration and significant nidus reduction, respectively.

http://thejns.org/doi/abs/10.3171/2016.7.GKS161549

KEY WORDS arteriovenous malformations; volume; Gamma Knife; hemorrhage; clinical outcome; vascular disorders; stereotactic radiosurgery

$\mathrm{T}$ HE optimal treatment strategy for cerebral arteriovenous malformations (AVMs) has been a matter of debate. ${ }^{6,10-13,15-18,20,23,27,29-32,35}$ The results of a randomized study on the treatment of unruptured AVMs has substantially changed the treatment strategy for asympto- matic patients, showing a significant increase of morbidity and mortality in patients treated with medical management plus interventional therapy as compared with medical management alone. ${ }^{18}$ Large AVMs, which represent a small percentage (10\%) of all AVMs, pose a formidable

ABBREVIATIONS AED = antiepileptic drug; $A U C=$ area under the curve; $A V M=$ arteriovenous malformation; $D S A=$ digital subtraction angiography; GKRS = Gamma Knife radiosurgery; $\mathrm{ROC}=$ receiver operating characteristic; $\mathrm{SM}=$ Spetzler-Martin.

SUBMITTED June 10, 2016. ACCEPTED July 27, 2016.

INCLUDE WHEN CITING DOI: 10.3171/2016.7.GKS161549. 
challenge. ${ }^{15}$ Their 5-year cumulative hemorrhage risk ranges from 5\% for unruptured AVMs up to $40 \%$ for AVMs that have previously ruptured. ${ }^{15}$ Resection is associated with a risk of permanent morbidity and/or death, ranging from $12 \%$ to $40 \%$; endovascular treatment, either transarterial or transvenous or in combination with microsurgery or stereotactic radiosurgery, has been associated with a reduced obliteration rate and an increased hemorrhage rate, although this has been debated. ${ }^{12,32}$ In addition, a recently published meta-analysis reported that SpetzlerMartin (SM) Grades III to V were independent risk factors for poor outcome after embolization. ${ }^{17}$ Theoretically, volume-staged radiosurgery could have the benefit of administering a high margin dose to the AVM nidus while maintaining a safe risk-profile. A few series report promising results using volume-staged radiosurgery for large cerebral AVMs. ${ }^{2,3,6,11,13,23,26,27}$ We think volume-staged radiosurgery should be considered the first line of treatment for these formidable cerebral vascular malformations, and here we report the results of our experience with such a treatment paradigm. Our aim was to analyze the outcome of volume-staged radiosurgery on large AVMs, and our results show how this strategy carries a significant lesion volume reduction and reasonably low complication rates.

\section{Methods}

\section{Study Population and Treatment Algorithm}

Twenty patients with large AVMs treated with volumestaged Gamma Knife radiosurgery (GKRS) between 2004 and 2012 were prospectively included in our AVM database, and the results were retrospectively evaluated. Ethics committee approval was not requested because this is a retrospective study derived from the review of a prospectively collected database. Demographics, medical history, and clinical presentation were recorded for each patient. All patients were subjected to stereotactic digital subtraction angiography (DSA) and MRI examination on the day of the programmed SRS treatment.

\section{DSA}

As part of the treatment plan, all patients underwent same-day biplanar DSA (Philips Allura FD 20/20) prior to volume-staged GKRS, with an image frame rate of 3 frames per second and injector-controlled contrast injection rates $\left(4 \mathrm{~cm}^{3} / \mathrm{sec}\right.$ for a total of $\left.8 \mathrm{~cm}^{3}\right)$. We examined angioarchitectural features on the arterial side: feeding artery enlargement (none/mild: feeding artery is the same size or only slightly more prominent than the contralateral vessel; dilated feeder: at least 1.5 times larger than the contralateral vessel), associated aneurysms, and perinidal angiogenesis as described by Valavanis and Yaşargil. ${ }^{31}$ The nidus was evaluated for volume (as determined from the original radiation plan based on cross-sectional imaging), location (eloquent vs noneloquent), nidus type (compact vs diffuse), and flow pattern (arteriovenous transit time), which was estimated by determining the number of DSA frames between the first depiction of the nidus and the first visualization of a vein (high flow: venous drainage appearing in the same frame as the AVM nidus or arterial feeders; moderate flow: 1-frame difference between visualization of the nidus and venous drainage; and low flow: venous drainage seen in $>2$ frames after nidal visualization). ${ }^{30}$ For each AVM we recorded the number of venous drainages (single vs multiple), their location (deep vs superficial), and the presence or absence of venous varices/stenoses. Each DS angiogram was examined by an interventional neuroradiologist with at least 10 years of experience. We never performed superselective microcatheterization of AVM arterial feeders for SRS treatment planning.

\section{Radiosurgery Treatment Plan}

The Elekta Leksell Gamma Knife model C was used until 2007 and was later replaced by the Elekta Leksell Gamma Knife Perfexion model. Treatment plans were generated using the GammaPlan system version 10.1.1. Patients underwent stereotactic volumetric MRI, T2-weighted MRI, and cerebral DSA prior to the first volume-staged GKRS session and were then transferred to the planning station for treatment optimization. Subsequently, the total AVM volume was estimated from the dose-planning software, which allowed us to define the number of stages and staging strategy. Volume staging is usually considered for volumes greater than or equal to $10 \mathrm{~cm}^{3}$. The nidus appearance on DSA is the key element when choosing which part to treat first. Typically, the first nidal portion to appear in the DSA frames is considered to be the core, and so it is usually irradiated first. This general rule can be modified in cases of venous drainage superpositions or a deepseated location of the nidal core. In such cases, we try to avoid irradiation of the main drainage to reduce the risk of hemorrhage prior to AVM closure. Similarly, any deepseated nidal portions are usually irradiated after the more superficial regions to try to maximize the treatment dose while minimizing potential adverse radiation effects. ${ }^{23}$ Two plans were made upfront to try to contour the whole AVM volume. The original treatment plan strategy is then reevaluated according to follow-up imaging at the time the second fraction is performed. In subsequent sessions, MRI and DSA are repeated, and the treatment plan from the first session is coregistered to the new imaging data set to avoid dose overlap in the brain parenchyma adjacent to the AVM and to anatomically match the 2 examinations and treatment plans. We staged volume-sessions to be able to administer at least $18 \mathrm{~Gy}$ at the $50 \%$ isodose during each stage (number of stages: 2). The time interval between stages was 6 to 12 months. Treatment plans were defined by the treating neurosurgeon, the radiation oncologist, and the medical physicist.

\section{Follow-Up}

Neurological examination and MRI were performed for each patient every 6 months for the first 2 years and then annually. DSA was proposed to all patients after 3 years of follow-up or as soon as MRI suggested complete or near-complete AVM obliteration. Nidus obliteration was defined as follows: complete when no residual nidus was visible on DSA or on MRI for patients who refused the angiographic examination; near-complete when a reduction of more than $90 \%$ of the original nidal volume was evident by DSA or MRI follow-up; subtotal when a 
reduction of more than $75 \%$ of the original nidal volume was not evident by DSA or MRI follow-up; and partial when the reduction was confined to $50 \%$ or less of the original nidal volume. The complication rate was updated at each follow-up visit. Modification of prior antiepileptic drug (AED) regimens was evaluated at each outpatient visit and recorded. Follow-up DSA was performed by an interventional neuroradiologist with at least 10 years of experience and compared with the original to verify eventual changes within the treated AVM.

\section{Statistical Analysis}

Descriptive statistics are displayed as mean $( \pm$ standard deviation), median, range, and percentages. Various factors that affect patient outcome were analyzed by comparing continuous variables with Mann-Whitney U-test and categorical variables with the Fisher's exact test. For continuous variables, receiver operating characteristic (ROC) curve analyses were used to assess the most predictive cutoff values through the corrected Youden index, and the discriminative power was measured by the area under the curve (AUC). The same continuous variables were then dichotomized according to the resulting cutoff, and their significance on obliteration was evaluated with the Fisher's exact test. A p value of $<0.05$ was considered statistically significant.

\section{Results \\ Patient Population}

Between January 2004 and January 2012, 20 patients (10 male and 10 female; median age at the time of first GKRS treatment was 38 years, range 16-59 years) underwent volume-staged radiosurgery for the treatment of their cerebral AVM. Eleven (55\%) patients had previously received endovascular treatment that resulted in incomplete obliteration of the AVM. The discovery of the cerebral AVM was due to neurological symptoms/signs in 17 (85\%) patients, steal phenomenon causing focal neurological deficits (hemianopsia, sensorimotor deficits, mnesic deficits, gait disturbances) in 7 (35\%), epileptic seizures in $8(40 \%)$, intracerebral hemorrhage in $6(30 \%)$, and intractable headache or unexplained dizziness/vertigo that led to diagnostic MRI evaluation in $3(5 \%)$. In the remaining $3(15 \%)$ patients, the cerebral AVM was incidentally discovered. Patient demographics and presentations are summarized in Table 1.

\section{AVM Features}

Mean and median AVM volume were 15.9 and $13.2 \mathrm{~cm}^{3}$, respectively (range 10.1-34.3 $\mathrm{cm}^{3}$ ). Nineteen $(95 \%)$ patients had AVMs located in the supratentorial region. The AVM was located in the frontal lobe in $3(15 \%)$ patients, the temporal lobe in $2(10 \%)$ patients, and the occipital lobe in $1(5 \%)$ patient. Twelve $(60 \%)$ AVMs were large enough to invade more than a single cerebral lobe. The thalamus, callosal body, and adjacent ventricular structures were involved in 1 (5\%) patient each. Fifteen (75\%) AVMs affected eloquent portions of the cerebral cortex. Cerebral AVMs were further evaluated according to the SM classification system. ${ }^{28}$ Ten (50\%) AVMs were classified as SM
TABLE 1. Patient demographics and clinical presenting features

\begin{tabular}{lcc}
\hline \multicolumn{1}{c}{ Variable } & No. & $\%$ \\
\hline Sex M/F & $10: 10$ & 50 \\
\hline Age in yrs at first GKRS (range) & $38(16-59)$ & NA \\
\hline Symptomatic & 17 & 85 \\
\hline Asymptomatic & 3 & 15 \\
\hline Focal deficit/steal effect & 7 & 35 \\
\hline Epilepsy & 8 & 40 \\
\hline Hemorrhage & 6 & 30 \\
\hline Intractable headache/vertigo & 3 & 15 \\
\hline NA = not applicable. & &
\end{tabular}

Grade III, 7 (35\%) as SM Grade IV, and $3(6 \%)$ as SM Grade V. AVM characteristics are outlined in Table 2.

A total of $16(85 \%)$ AVMs scored $>2$ on the PollockFlickinger scale; ${ }^{21}$ the remaining $4(15 \%)$ scored between 1.51 and 2.00. Angioarchitectural features are outlined in Table 3. A high flow rate was detected by angiography in $13(70 \%)$ patients, moderate flow rate in $5(25 \%)$, and low flow rate in $1(5 \%)$. Nidal morphology was considered to be compact in $3(15 \%)$ patients, while the vast majority $(17 / 20 ; 85 \%)$ displayed features suggestive of perinidal neoangiogenesis associated with a diffuse nidal angiographic pattern. All direct feeders evaluated via selective catheterization were dilated; feeders were present in a superficial (i.e., cortical) territory in $10(50 \%)$ patients, a deep location in $1(5 \%)$, and in a mixed superficial and deep location in $9(45 \%)$. Venous drainage was deep seated in $3(15 \%)$ patients, superficial in $6(30 \%)$, and mixed in $11(55 \%)$. Single drainage was detected in $7(37 \%)$ patients,

\section{TABLE 2. Summary of AVM features}

\begin{tabular}{|c|c|c|}
\hline Variable & No. (range) & $\%$ \\
\hline Median vol of AVM in $\mathrm{cm}^{3}$ & $15.9(10.1-34.3)$ & NA \\
\hline \multicolumn{3}{|l|}{ Lobe } \\
\hline Temporal & 2 & 10 \\
\hline Frontal & 3 & 15 \\
\hline Occipital & 1 & 5 \\
\hline Posterior fossa & 1 & 5 \\
\hline Thalamic & 1 & 5 \\
\hline Diffuse & 12 & 60 \\
\hline Eloquent & 15 & 75 \\
\hline Prior embolization & 11 & 55 \\
\hline Interval btwn stages in mos & $13(8-32)$ & \\
\hline \multicolumn{3}{|l|}{ SM grade } \\
\hline III & 10 & 50 \\
\hline IV & 7 & 35 \\
\hline V & 3 & 15 \\
\hline \multicolumn{3}{|l|}{ Pollock-Flickinger scale score } \\
\hline$>2$ & 16 & 80 \\
\hline $1.5-2$ & 4 & 20 \\
\hline $1-1.5$ & 0 & 0 \\
\hline
\end{tabular}


TABLE 3. AVM angioarchitecture

\begin{tabular}{|c|c|c|}
\hline Variable & No. & $\%$ \\
\hline \multicolumn{3}{|l|}{ Flow } \\
\hline High & 13 & 69 \\
\hline Moderate & 5 & 26 \\
\hline Low & 1 & 5 \\
\hline \multicolumn{3}{|l|}{ Drainage } \\
\hline Superficial & 6 & 30 \\
\hline Deep & 3 & 15 \\
\hline Mixed & 11 & 55 \\
\hline \multicolumn{3}{|l|}{ Drainage } \\
\hline Single & 7 & 37 \\
\hline Multiple & 12 & 63 \\
\hline \multicolumn{3}{|l|}{ Nidus } \\
\hline Compact & 3 & 15 \\
\hline Diffuse* & 17 & 85 \\
\hline \multicolumn{3}{|c|}{ Venous dilation/aneurysms } \\
\hline Present & 4 & 24 \\
\hline Absent & 13 & 76 \\
\hline \multicolumn{3}{|l|}{ Venous stenosis } \\
\hline Present & 1 & 5 \\
\hline Absent & 19 & 95 \\
\hline \multicolumn{3}{|l|}{ Feeders location } \\
\hline Deep & 1 & 5 \\
\hline Mixed & 9 & 45 \\
\hline Superficial & 10 & 50 \\
\hline \multicolumn{3}{|l|}{ Feeders dilation } \\
\hline Yes & 20 & 100 \\
\hline No & 0 & 0 \\
\hline
\end{tabular}

* With associated features of perinidal angiogenesis.

while the majority $(12 ; 63 \%)$ showed multiple, dilated, venous drainages. Venous varices were noted in $4(20 \%)$ patients, while venous stenosis was only detected in $1(5 \%)$ patient. Five $(20 \%)$ patients presented with flow-related aneurysmal malformations on 1 of the afferent nidal arteries. Ten $(50 \%)$ of the treated AVMs showed surrounding parenchymal edema at the baseline MRI study.

\section{Gamma Knife Treatment}

The median total AVM volume was $15.9 \mathrm{~cm}^{3}$ (mean $13.2 \mathrm{~cm}^{3}$, range $10.1-34.3 \mathrm{~cm}^{3}$ ). AVMs were treated with 2 fractions of GKRS, with a mean interval between fractions of $15 \pm 6$ months. The mean target volume was 8.00 $\pm 3.78 \mathrm{~cm}^{3}$ for the first fraction and $5.00 \pm 2.19 \mathrm{~cm}^{3}$ for the second fraction; the mean prescription dose was 20 \pm 2 Gy at the $50 \%$ isodose, with $96 \%$ and $97 \%$ volume coverage during the first and second session, respectively. Treatment variables are presented in Table 4.

\section{Obliteration Rates}

Thirteen (68\%) patients underwent DSA at last followup (Table 5). The remaining $6(32 \%)$ refused DSA and were evaluated by MRI. One patient was lost to followup. Obliteration of the AVM nidus was confirmed in 8/19 (42\%) patients. Four (21\%) patients had an AVM volume reduction of more than $75 \%$ at last angiographic follow-up,
TABLE 4. GKRS features*

\begin{tabular}{lll}
\hline & \multicolumn{2}{c}{ Vol-Staged GKRS } \\
\cline { 2 - 3 } Parameter & \multicolumn{1}{c}{ 1st Stage } & 2nd Stage \\
\hline Target vol $\left(\mathrm{cm}^{3}\right)$ & $7.8(2.7-15.8)$ & $4.7(0.8-10.6)$ \\
\hline Margin dose $(\mathrm{Gy})$ & $20(18-25)$ & $20(13-24)$ \\
\hline Max dose (Gy) & $40(36-50)$ & $41(26-49)$ \\
\hline No. of isocenters & $17(5-26)$ & $13(4-24)$ \\
\hline V12 $\left(\mathrm{cm}^{3}\right)$ & $24.3(14.3-42.7)$ & $15.5(0.2-32.6)$ \\
\hline V10 $\left(\mathrm{cm}^{3}\right)$ & $32.1(18.7-55.5)$ & $21.6(0.4-41.8)$ \\
\hline$\%$ coverage & $96(90-100)$ & $97(91-100)$ \\
\hline V10 = volume receiving 10 Gy; V12 = volume receiving 12 Gy. \\
* Values are presented as the median (range).
\end{tabular}

while the same proportion (21\%) showed a $50 \%$ volume reduction. In $3(16 \%)$ patients, the AVM volume was unchanged after 2 SRS sessions. On univariate analysis, high nidal flow and a shorter interval between radiosurgical sessions (less than 11 months as a dichotomized variable) were significantly associated with higher obliteration rates at last follow-up ( $\mathrm{p}=0.021$ and $\mathrm{p}=0.041$, respectively; Table 6). Other angioarchitectural variables, pre-GKRS embolization, hemorrhage, patient age, or AVM volume were not statistically associated with GKRS outcome at followup. Younger patient age ( $\leq 44$ years) was significantly associated with a strong response to radiosurgical treatment ( $>75 \%$ reduction in nidal volume; $p=0.024$ ) but was not associated with AVM obliteration at last follow-up.

\section{Clinical Follow-Up After Volume-Staged Radiosurgery}

Clinical follow-up was available for 19 patients (1 was lost to follow-up). Four (50\%) of 8 patients reported a complete disappearance of epileptic seizures, allowing them to stop AEDs. Two (25\%) of 8 reported a reduction in seizure frequency, while the same proportion $(1 / 8 ; 12.5 \%)$ reported no change in both frequency and intensity of epileptic discharges. Among the 6 patients who presented acutely due to intracerebral bleeding, none experienced a rebleeding episode during the follow-up period. Of the 7 patients who presented with focal neurological deficits, 2 (28.5\%) experienced a complete recovery, 3 (43\%) reported improvement, and $2(28.5 \%)$ reported no change. Regarding adverse events during follow-up, 1 (5.2\%) patient developed radionecrosis partially affecting the cortical motor area, which caused contralateral hemicorporeal motor deficit; this patient is still slowly recovering after more than 1 year of physiotherapy kinesiotherapy. Intracerebral hemorrhages were detected in $2(10.5 \%)$ patients during follow-up, and in 1 patient the bleeding episode was severe enough to cause a focal deficit (namely, homonymous hemianopia). Both bleeding episodes were managed conservatively. New epileptic seizures developed in $2(10.5 \%)$ patients, and both frequency and intensity of epileptic episodes were controlled by AEDs. Sporadic paresthesias and tinnitus-like auditory disturbances occurred in 1 (5.3\%) patient each. Clinical follow-up is reported in Table 5. Table 7 shows patients' clinical history and GKRS details/outcome data. 
TABLE 5. Patient outcomes and follow-up

\begin{tabular}{lcc}
\hline \multicolumn{1}{c}{ Variable } & No. & $\%$ \\
\hline Median follow-up in mos. (range) & $45(19-87)$ & NA \\
\hline DSA at follow-up & 13 & 68 \\
\hline MRI at follow-up & 6 & 32 \\
\hline Total obliteration & 8 & 42 \\
\hline$>75 \%$ occlusion & 4 & 20 \\
\hline $50 \%$ occlusion & 4 & 20 \\
\hline AVM vol unchanged & 3 & 15 \\
\hline Hemorrhage & 2 & 10 \\
\hline Seizures & & \\
Completely resolved (Engel Class I) & 4 & 50 \\
Ameliorated (Engel Class II) & 2 & 25 \\
Stable & 1 & 12.5 \\
\hline Neurological deficit & & \\
Completely recovered & 2 & 28.5 \\
Improved & 3 & 43 \\
Unchanged & 2 & 28.5 \\
\hline Complications & & \\
Hemisyndrome & 1 & 5.2 \\
Radionecrosis & 1 & 5.2 \\
Hemorrhage & 2 & 10.5 \\
Symptomatic hemorrhage & 1 & 5.2 \\
\hline
\end{tabular}

\section{Discussion}

The management of large AVMs is a formidable challenge. Hypofractionated stereotactic radiotherapy has been described as an adjunctive strategy for reducing giant (e.g., $>5 \mathrm{~cm}$ ) AVMs, making them amenable to singledose radiosurgery. ${ }^{34}$ Staged GKRS has been described as an effective strategy for the management of these dreadful vascular lesions. A recent systematic review on the subject suggested that volume-staging is a potentially superior approach to dose-staging for GKRS, based on higher obliteration rates and similar complication rates. ${ }^{19} \mathrm{~A}$ few studies have shown promising results in terms of obliteration rates and adverse events following volume-staged SRS for large cerebral AVMs. Our obliteration rate of $42 \%$ is in line with results previously reported by others, ${ }^{2,3,6,11,13,23,26,27}$ which range from $10 \%$ to $62 \%$ for series describing more than 10 patients. A significant proportion of our patients had a nidus characterized by diffuse morphology and features of perinidal angiogenesis and high nidal flow; these features are associated with a lower rate of postradiosurgical obliteration. ${ }^{20,30,35}$ Interestingly, Paúl et al. recently published the largest series to date evaluating angiographic predictors of AVM obliteration. In that study, the authors acknowledged the presence of a higher obliteration rate for high-flow AVMs; a high flow rate can decrease the obliteration rate only within a given volume-i.e., for two AVMs with the same volume, there is a greater chance for obliteration in the low-flow AVM. ${ }^{20}$ In our reported population of large, complex AVMs, high flow was found to be an angiographic predictor of AVM obliteration on follow-up. Considering the dynamic process of radiosurgical treatment for large, cerebral AVMs, it is reasonable to expect even higher obliteration rates with longer follow-up. This has been clearly shown by Huang et al. ${ }^{11}$ and Kano et al. ${ }^{13}$ in 2012: in both papers the authors used Kaplan-Meier curves to show a progressive increase in the total obliteration rate over time. In particular, Huang et al. showed a $29 \%$ obliteration rate by 5 years and up to $89 \%$ at 10 years. However, in our univariate analysis there was no correlation between time and obliteration, probably because of the small number of patients. Interestingly, MRI suggested complete AVM obliteration in 2 patients whose angiographic control showed the persistence of a single, small draining vein without the presence of a nidus-like pattern. This particular feature has been found several other times in our experience (unpublished data), and we think it represents the last remaining part of the microvascular shunt. We classified those patients within the complete obliteration subgroup, and we scheduled a follow-up DSA after 12 months. (Figure 1 shows an example of a persistent single draining vein, and Fig. 2 shows a complete response.) The management of patients who show residual AVM filling volume at last follow-up is challenging and currently debated. Many options are theoretically available within the armamentarium of the treating neurosurgeon. Resection of an AVM previously reduced by GKRS can be an effective option, as reported by Seymour et al. ${ }^{26}$ Repeating a radiosurgical procedure can also be an effective option, so long as it is technically feasible according to the previously irradiated volumes and dosimetry plan, and adverse event risks are carefully weighed.

In our institution, the treatment choice is routinely made on a case-by-case basis according to benefits and risks related to volume, location, potential surgical morbidity, angiographic features such as the presence of related aneurysms, and the patient's choice. Patients who are not amenable to or who refused post-GKRS treatment are monitored by annual follow-up. Hemorrhage prevention is a key element in cerebral AVM treatment, and the risk of rupture or rehemorrhage of a previously ruptured AVM theoretically remains until its obliteration; this has long been mentioned as a "weakness" of radiosurgical treatment. This is particularly true when dealing with large AVMs. Large nidus size, diffuse nidus on angiography, and previous hemorrhages have all been reported as risk factors for

TABLE 6. Statistical analyses

\begin{tabular}{lcc}
\hline \multicolumn{1}{c}{ Factor } & \multicolumn{2}{c}{ Outcome } \\
\cline { 2 - 3 } & AVM Obliteration & AVM Reduction $>75 \%$ \\
\hline Nidal flow & $p=0.021$ & $\leq 44$ yrs $($ AUC $=0.76) ; p=0.024$ \\
\hline Age & & \\
\hline Time btwn GKRS fractions & $\leq 11.7 \operatorname{mos}($ AUC $=0.72) ; p=0.041$ & \\
\hline
\end{tabular}




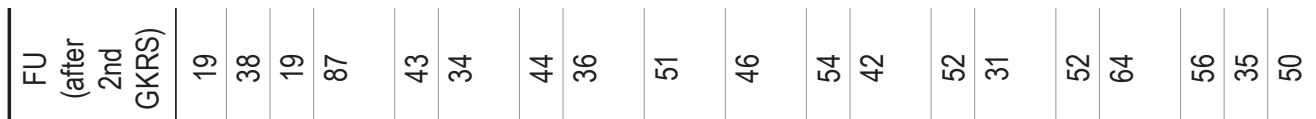
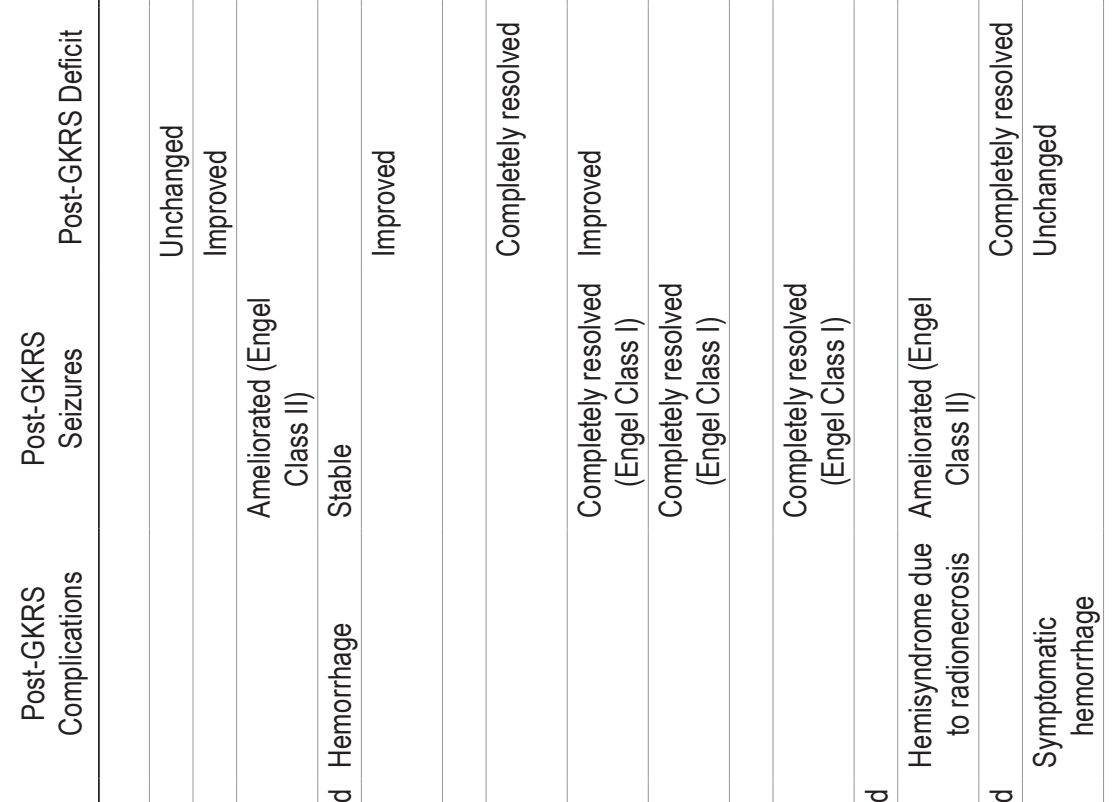

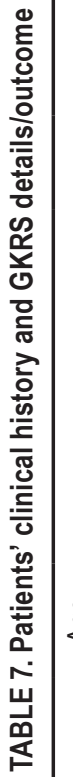

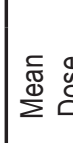
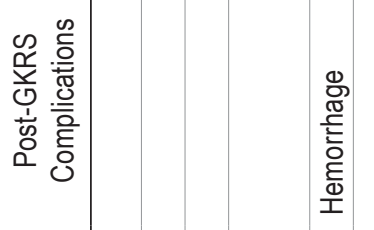

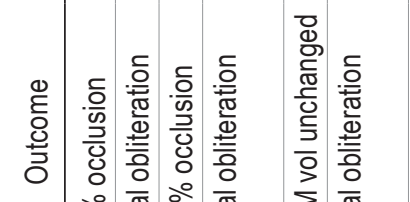

吕

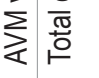

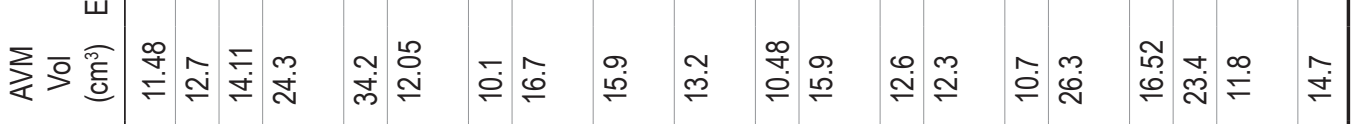

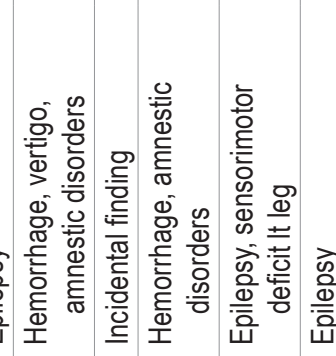



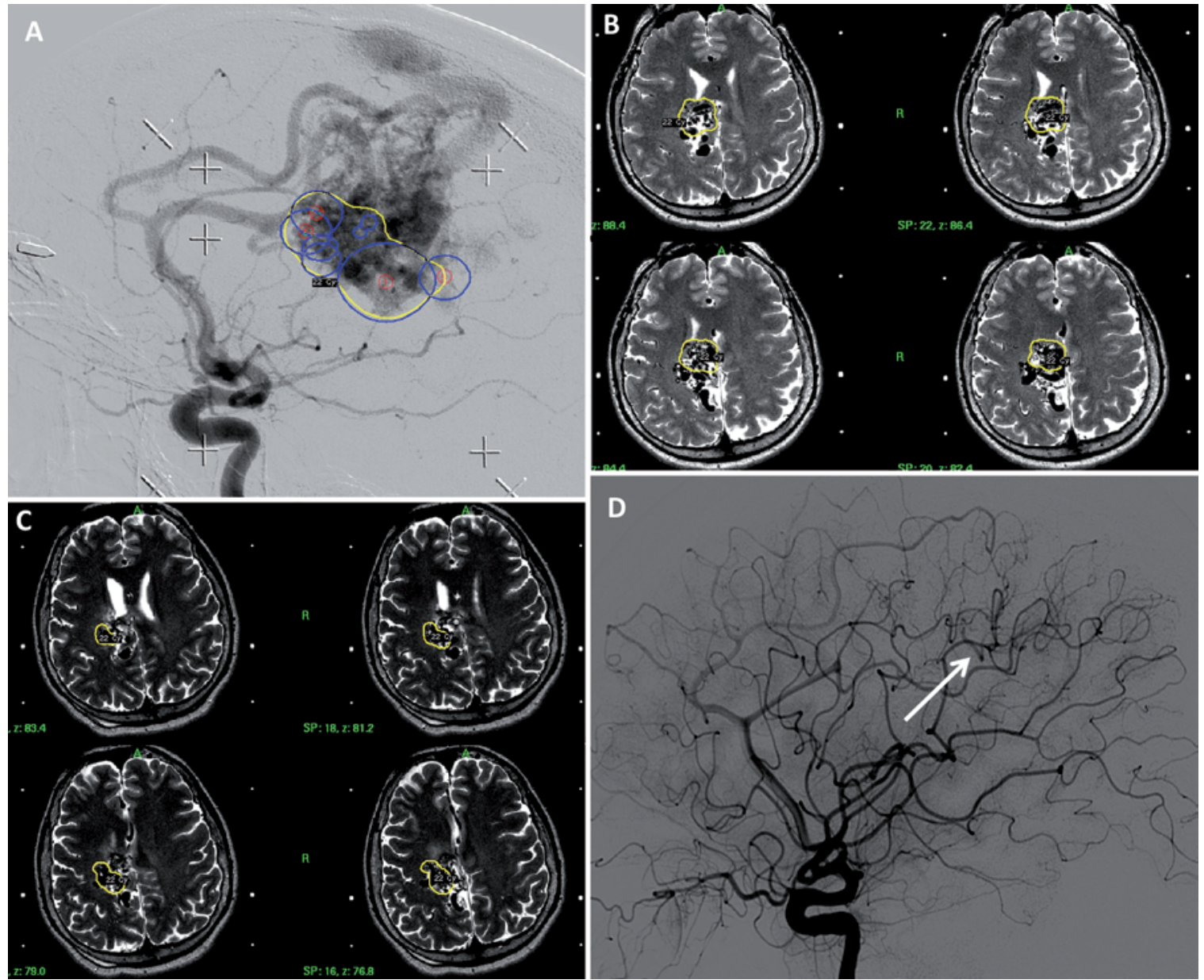

FIG. 1. Patient who responded to GKRS with extreme reduction of the AVM. A: Pretreatment DS angiogram (first fraction) showing the malformation nidus. B: Treatment planning on MRI (first fraction) showing the malformation nidus and the GKRS treatment (50\% of the isodose outlined in yellow). C: Treatment planning on MRI (second fraction) showing the malformation nidus and the GKRS treatment (50\% of the isodose outlined in yellow). D: Follow-up DS angiogram at 46 months after the first fraction treatment, showing complete obliteration of the AVM nidus and only an early vein draining into the superior sagittal sinus, filled by the contrast medium during the arterial phase (white arrow).

rupture/rerupture by several experienced groups. ${ }^{1,8-10,22,28}$ In previously reported series of volume-staged GKRS treatment for AVMs, the postradiosurgical hemorrhage rate ranged from $14.2 \%$ up to $27.7 \% .^{2,3,6,11,13,23,26,27}$ In addition, Huang et al. ${ }^{11}$, Sirin et al. ${ }^{31}$, and Kano et al. ${ }^{13}$ detailed neurological outcomes for patients who suffered a postradiosurgical bleeding episode: 8/19 (42\%) deaths were reported overall. In our series, none of the patients who presented acutely with intracerebral hemorrhage experienced a rebleeding episode, and we discovered only 2 (10\%) patients who suffered from a bleeding episode after radiosurgery. In our experience, both episodes were neurologically mild without leaving permanent incapacitating deficits. A higher margin dose, a careful analysis of the pretreatment DSA, and shielding of the venous drainage while defining the plan could be factors related to the low hemorrhage rate reported in our series. Hemorrhage characteristics (e.g., significant subarachnoid hemorrhage or pure intraventricular bleeding when choroidal feeders are involved by the AVM nidus) should prompt aggressive diagnostics, such as superselective microcatheterization, and treatment of eventual ruptured associated aneurysms. Neurological deficits secondary to hemodynamic/steal effects or seizures can be severe enough to incapacitate patients' lives, especially considering the dramatic effect that large AVMs can exert on the cerebral circulation. Considering the inherent difficulty of achieving a complete obliteration for such challenging lesions, seizure control and prevention of neurological deficit progression are key objectives in the radiosurgical treatment of large AVMs. The dramatic positive effect of radiosurgical treatment on seizure outcome has been previously reported to be up to $80 \%{ }^{4,7,24,33}$ and related to obliteration. This also holds true for large cerebral AVMs, as we reported $50 \%$ of patients to be seizure-free (Engel Class I) and 25\% to have a significant reduction in epileptic episodes (Engel Class II), thereby achieving an overall good outcome in seizure control for $75 \%$. We did find a significant amelioration of neurological deficits in the reported population; in particular, 5/7 (71.4\%) patients who presented with neurological deficits due to AVM hemodynamics/steal phenomenon experienced a resolution $(2 / 7 ; 28.5 \%)$ or improvement $(3 / 7$; 

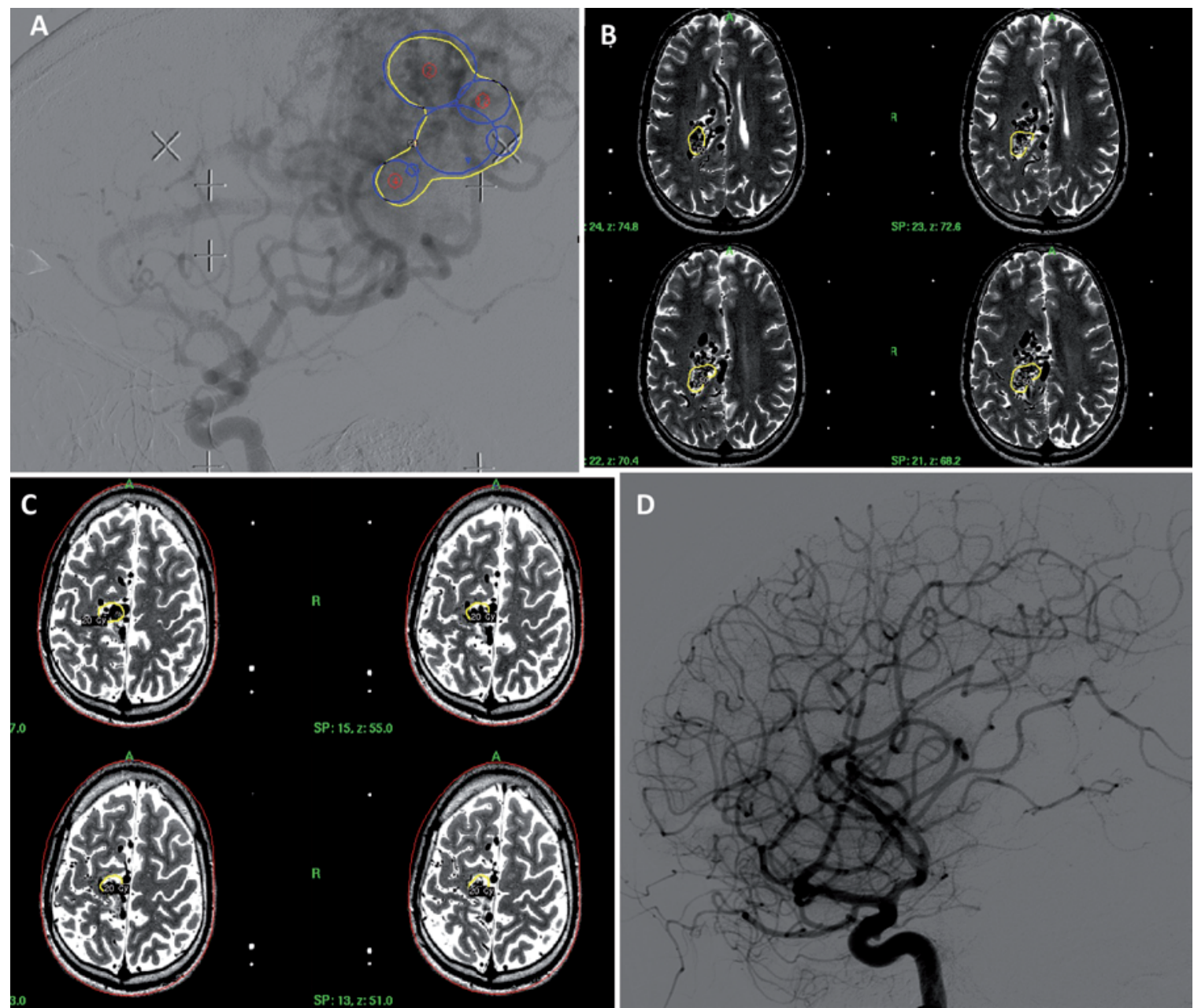

FIG. 2. Patient who responded to GKRS with complete obliteration of the AVM. A: Pretreatment DS angiogram (first fraction) showing the malformation nidus. B: Treatment planning on MRI (first fraction) showing the malformation nidus and the GKRS treatment ( $50 \%$ of the isodose outlined in yellow). C: Treatment planning on MRI (second fraction) showing the malformation nidus and the GKRS treatment (50\% of the isodose outlined in yellow). D: Complete obliteration of the AVM, as seen on follow-up DS angiogram, at 61 months after the first fraction treatment.

42.8\%) in their neurological signs/symptoms. Neither the length of follow-up nor AVM obliteration was statistically associated with this neurological improvement, although we attributed the beneficial effects to modifications in AVM hemodynamics, leading to a reduced steal effect on the cerebral circulation. ${ }^{25}$ Adverse effects of radiation traditionally represented a key problem in the radiosurgical management of large cerebral AVMs. Adverse radiation effects have been associated with a large nidus and a higher margin dose, among other factors.,14 Historically, the volume-staging strategy emerged to enable the administration of a higher global dose to a large volume while maintaining a low rate of adverse effects. ${ }^{23}$ With the exception of Dalyai et al. ${ }^{6}$, we administered a higher margin dose than the vast majority of reported series for volumestaged fractionation of large cerebral AVMs (20 Gy at the $50 \%$ isodose), and we used a longer time interval between stages. The long mean interval between sessions $(15 \pm 6$ months) is explained by 4 patients who initially refused the second treatment and later accepted it. According to our results, high doses in the reported range are safe and feasible, even when treating large AVMs, as evidenced by the low overall rate $(2 / 19,10.5 \%)$ of adverse radiation effects in the present series, with only $1(5 \%)$ patient who experienced a new persistent neurological deficit. This compares positively with the reported range of adverse effects or complications $(11.2 \%-14 \%)$ in other series of volume-staged radiosurgery. $2,3,6,11,13,23,26,27$ On the contrary, we are currently modifying our treatment algorithm to shorten the time interval between stages so it is in greater alignment with that reported by others. . $^{2,3,6,11,13,23,26,27}$ Fiftyfive percent of the reported population had been subjected to endovascular embolization prior to volume-staged radiosurgery. This has been reported to be potentially associated with reduced obliteration rates, likely due to more difficult nidus targeting and hemodynamic effects rather than volume-decreasing ones. We did not find any statistically significant association between prior embolization and obliteration rate. This has been previously shown in literature; in particular, Huang et al. presented the longest follow-up available ${ }^{11}$ and reported similar cumulative closure rates for the 2 groups (embolized vs not embolized). 
Total AVM volume per se has been reported both to be and not to be strongly related to obliteration rate. In the series presented by Kano et al., "small" AVM volume was associated with increased obliteration rates in univariate analysis only, without being confirmed in multivariate analysis. ${ }^{13}$ On the contrary, Seymour et al. found AVM volume to be predictive of AVM obliteration in multivariate analysis. ${ }^{26}$ Even though our results are weakened by the inherent limitations associated with low patient numbers, AVM volume was not found to be predictive of total obliteration; this finding is probably due to similar AVM volumes among the majority of our reported population, making it difficult to stratify volume in such a way as to infer a statistically significant effect. Our study has several limitations. First, single-center studies can be subject to selection bias. Second, the low number of patients prevents us from being able to generalize our results. The relative shortness of our follow-up period (45 months [range 19-87 months]) may have led us to an underestimation of adverse effects, e.g., delayed cyst formation. Our patient follow-up will continue for at least 5 years after AVM obliteration. Still, it is our belief that the results presented here can add valuable data to the available literature concerning this promising treatment strategy.

\section{Conclusions}

A high margin dose can be administered with a safe profile of adverse effects and be effective in obliterating or at least significantly reducing large, complex, cerebral AVMs. Volume-staged SRS can dramatically ameliorate the clinical picture for these patients for whom there are often only few, if any, other therapeutic options. In conclusion, good obliteration rates, a significant impact on seizures, and reduced neurological deficits with an acceptable rate of complications are the key elements that make volume-staged radiosurgery the first-line treatment strategy for complex, large, cerebral AVMs.

\section{References}

1. Abecassis IJ, Xu DS, Batjer HH, Bendok BR: Natural history of brain arteriovenous malformations: a systematic review. Neurosurg Focus 37(3):E7, 2014

2. AlKhalili K, Chalouhi N, Tjoumakaris S, Rosenwasser R, Jabbour P: Staged-volume radiosurgery for large arteriovenous malformations: a review. Neurosurg Focus 37(3):E20, 2014

3. Back AG, Vollmer D, Zeck O, Shkedy C, Shedden PM: Retrospective analysis of unstaged and staged Gamma Knife surgery with and without preceding embolization for the treatment of arteriovenous malformations. J Neurosurg 109 Suppl:57-64, 2008

4. Baranoski JF, Grant RA, Hirsch LJ, Visintainer P, Gerrard JL, Günel M, et al: Seizure control for intracranial arteriovenous malformations is directly related to treatment modality: a meta-analysis. J Neurointerv Surg 6:684-690, 2014

5. Cohen-Inbar O, Lee CC, Xu Z, Schlesinger D, Sheehan JP: A quantitative analysis of adverse radiation effects following Gamma Knife radiosurgery for arteriovenous malformations. J Neurosurg 123:945-953, 2015

6. Dalyai R, Theofanis T, Starke RM, Chalouhi N, Ghobrial G, Jabbour P, et al: Stereotactic radiosurgery with neoadjuvant embolization of larger arteriovenous malformations: an institutional experience. BioMed Res Int 2014:306518, 2014
7. Ditty BJ, Omar NB, Foreman PM, Miller JH, Kicielinski KP, Fisher WS III, et al: Seizure outcomes after stereotactic radiosurgery for the treatment of cerebral arteriovenous malformations. J Neurosurg [epub ahead of print], 2016

8. Flores BC, Klinger DR, Rickert KL, Barnett SL, Welch BG, White JA, et al: Management of intracranial aneurysms associated with arteriovenous malformations. Neurosurg Focus 37(3):E11, 2014

9. Fults D, Kelly DL Jr: Natural history of arteriovenous malformations of the brain: a clinical study. Neurosurgery 15:658-662, 1984

10. Hernesniemi JA, Dashti R, Juvela S, Väärt K, Niemelä M, Laakso A: Natural history of brain arteriovenous malformations: a long-term follow-up study of risk of hemorrhage in 238 patients. Neurosurgery 63:823-831, 2008

11. Huang PP, Rush SC, Donahue B, Narayana A, Becske T, Nelson PK, et al: Long-term outcomes after staged-volume stereotactic radiosurgery for large arteriovenous malformations. Neurosurgery 71:632-644, 2012

12. Iosif C, Mendes GA, Saleme S, Ponomarjova S, Silveira EP, Caire F, et al: Endovascular transvenous cure for ruptured brain arteriovenous malformations in complex cases with high Spetzler-Martin grades. J Neurosurg 122:1229-1238, 2015

13. Kano H, Kondziolka D, Flickinger JC, Park KJ, Parry PV, Yang HC, et al: Stereotactic radiosurgery for arteriovenous malformations, Part 6: multistaged volumetric management of large arteriovenous malformations. J Neurosurg 116:5465,2012

14. Kano H, Kondziolka D, Flickinger JC, Yang HC, Flannery TJ, Awan NR, et al: Stereotactic radiosurgery for arteriovenous malformations, Part 3: outcome predictors and risks after repeat radiosurgery. J Neurosurg 116:21-32, 2012

15. Laakso A, Dashti R, Juvela S, Isarakul P, Niemelä M, Hernesniemi J: Risk of hemorrhage in patients with untreated Spetzler-Martin grade IV and V arteriovenous malformations: a long-term follow-up study in 63 patients. Neurosurgery 68:372-378, 2011

16. Lawton MT: Seven AVMs: Tenets and Techniques for Resection. New York: Thieme, 2014, pp 313-317

17. Ledezma CJ, Hoh BL, Carter BS, Pryor JC, Putman CM, Ogilvy CS: Complications of cerebral arteriovenous malformation embolization: multivariate analysis of predictive factors. Neurosurgery 58:602-611, 2006

18. Mohr JP, Parides MK, Stapf C, Moquete E, Moy CS, Overbey JR, et al: Medical management with or without interventional therapy for unruptured brain arteriovenous malformations (ARUBA): a multicentre, non-blinded, randomised trial. Lancet 383:614-621, 2014

19. Moosa S, Chen CJ, Ding D, Lee CC, Chivukula S, Starke $\mathrm{RM}$, et al: Volume-staged versus dose-staged radiosurgery outcomes for large intracranial arteriovenous malformations. Neurosurg Focus 37(3):E18, 2014

20. Paúl L, Casasco A, Kusak ME, Martinez N, Rey G, Martinez R: Results for a series of 697 arteriovenous malformations treated by Gamma Knife: influence of angiographic features on the obliteration rate. Neurosurgery 75:568-563, 583, 2014

21. Pollock BE, Flickinger JC: A proposed radiosurgery-based grading system for arteriovenous malformations. J Neurosurg 96:79-85, 2002

22. Pollock BE, Flickinger JC, Lunsford LD, Bissonette DJ, Kondziolka D: Factors that predict the bleeding risk of cerebral arteriovenous malformations. Stroke 27:1-6, 1996

23. Pollock BE, Kline RW, Stafford SL, Foote RL, Schomberg PJ: The rationale and technique of staged-volume arteriovenous malformation radiosurgery. Int J Radiat Oncol Biol Phys 48:817-824, 2000

24. Schäuble B, Cascino GD, Pollock BE, Gorman DA, Weigand 
S, Cohen-Gadol AA, et al: Seizure outcomes after stereotactic radiosurgery for cerebral arteriovenous malformations. Neurology 63:683-687, 2004

25. Schuster L, Schenk E, Giesel F, Hauser T, Gerigk L, ZabelDu-Bois A, et al: Changes in AVM angio-architecture and hemodynamics after stereotactic radiosurgery assessed by dynamic MRA and phase contrast flow assessments: a prospective follow-up study. Eur Radiol 21:1267-1276, 2011

26. Seymour ZA, Sneed PK, Gupta N, Lawton MT, Molinaro AM, Young W, et al: Volume-staged radiosurgery for large arteriovenous malformations: an evolving paradigm. J Neurosurg 124:163-174, 2016

27. Sirin S, Kondziolka D, Niranjan A, Flickinger JC, Maitz AH, Lunsford LD: Prospective staged volume radiosurgery for large arteriovenous malformations: indications and outcomes in otherwise untreatable patients. Neurosurgery 62 (Suppl 2):744-754, 2008

28. Spetzler RF, Martin NA: A proposed grading system for arteriovenous malformations. J Neurosurg 65:476-483, 1986

29. Stefani MA, Porter PJ, terBrugge KG, Montanera W, Willinsky RA, Wallace MC: Large and deep brain arteriovenous malformations are associated with risk of future hemorrhage. Stroke 33:1220-1224, 2002

30. Taeshineetanakul P, Krings T, Geibprasert S, Menezes R, Agid R, terBrugge KG, et al: Angioarchitecture determines obliteration rate after radiosurgery in brain arteriovenous malformations. Neurosurgery 71:1071-1079, 2012

31. Valavanis A, Yaşargil MG: The endovascular treatment of brain arteriovenous malformations. Adv Tech Stand Neurosurg 24:131-214, 1998

32. van Beijnum J, van der Worp HB, Buis DR, Al-Shahi Salman R, Kappelle LJ, Rinkel GJ, et al: Treatment of brain arteriovenous malformations: a systematic review and meta-analysis. JAMA 306:2011-2019, 2011

33. Walczak T: Surgical Treatment of the Epilepsies, ed 2. New York: Raven Press, 1994

34. Xiao F, Gorgulho AA, Lin CS, Chen CH, Agazaryan N, Viñuela $\mathrm{F}$, et al: Treatment of giant cerebral arteriovenous mal- formation: hypofractionated stereotactic radiation as the first stage. Neurosurgery 67:1253-1259, 2010

35. Zipfel GJ, Bradshaw P, Bova FJ, Friedman WA: Do the morphological characteristics of arteriovenous malformations affect the results of radiosurgery? J Neurosurg 101:393-401, 2004

\section{Disclosures}

The authors report no conflict of interest concerning the materials or methods used in this study or the findings specified in this paper.

\section{Author Contributions}

Conception and design: Franzin, Panni, Spatola, Mortini. Acquisition of data: Panni, Spatola, Gigliotti, Donofrio. Analysis and interpretation of data: Panni, del Vecchio, Gallotti, Gigliotti, Cavalli. Drafting the article: Franzin, Panni, Spatola, del Vecchio, Gallotti. Critically revising the article: Franzin, Panni, del Vecchio, Cavalli, Mortini. Reviewed submitted version of manuscript: all authors. Approved the final version of the manuscript on behalf of all authors: Franzin. Statistical analysis: Gallotti, Gigliotti.

\section{Supplemental Information \\ Previous Presentations}

A portion of this study was presented at the Leksell Gamma Knife Society 2016 meeting, Amsterdam, the Netherlands, May $18,2016$.

\section{Correspondence}

Alberto Franzin, Department of Neurosurgery and Radiosurgery, IRCCS San Raffaele Scientific Institute, Via Olgettina 60, Milan 20132, Italy.email: franzin.alberto@hsr.it. 